\title{
ESCULTURA PÚBLICA Y LA CÚPULA DE LA BASÍLICA DE LOURDES DE SANTIAGO
}

\section{Enrigue Solanich SOTOMaYor*}

\section{LOS AÑOS CUARENTA DEL SIGLO XX}

A fines de la década del treinta el panorama mundial es inquietante. Europa en guerra y azuzada por la Alemania beligerante, tiñe su desasosiego a los otros continentes. España, aún desgarrada por una confrontación interna junto a América, son atónitos espectadores del conflicto.

El año 1937 es hito en la historia de las artes visuales contemporáneas. Dos acontecimientos son claves en la revisión de los hechos. Uno, la exposición de arte degenerado hecha en Munich y organizada por la Nacional Socialista para desacreditar las vanguardias plásticas y expurgar de ellas las imágenes díscolas y aberrantes del modernismo de posguerra. Otro, cual contrapartida, la organización de la Exposición Internacional de París. Dos artistas exponen obras en el pabellón de España, que reformulan en gran medida, los procedimientos e imaginerías del arte del momento.

Se tratan de "Guernica" de Pablo Picasso (1881-1973) y "La Monserrat", de Julio González (1876-1942). El primero es un grito de indignación proclamado tras el bombardeo del pueblo vasco, el día 26 de abril por la avia ción alemana. El descomunal lienzo épico, es resumen, además, de la propia iconografía llevada a cabo durante cuatro décadas. La escultura "La Monserrat", hierro batido y soldado, es la figuración de una joven mujer que en el brazo izquierdo porta a su hijo y, en el derecho, una hoz. De improvisado

\footnotetext{
* Magíster en Teoría e Historia del Arte y Miembro de la Asociación Internacional de Críticos de Arte. Profesor de Historia del Arte en Facultad de Ciencias Físicas y Matemáticas de la Universidad de Chile.E-mail: enriquesolanich@hotmail.com
} 
Musicales, dependiente de la Facultad de Bellas Artes. Durante 1945 se destaca la apertura del Departamento de Extensión Popular Universidad Valentín Letelier. Y, por último, el año 1947 se funda el Museo de Arte Contemporáneo, corolario de los afanes de modernidad y transferencias culturales reseñadas ${ }^{2}$.

De las obras escultóricas de envergadura asentadas en el espacio urbano en el transcurso del decenio, cabe hacer mención a las siguientes: de Lorenzo Domínguez (1901-1963) Monumento al Doctor Luis Calvo Mackenna, en 1941; de Raúl Vargas Madariaga (1907-1990), el Homenaje a Rubén Darío; de Samuel Román Rojas el Monumento a las educadoras Isabel Lebrun y Antonio Tarragó en 1946; de Tótila Albert (1892-1967) la ornamentación para la tumba del Presidente Pedro Aguirre Cerda, en 1947 y del mismo Román el monumento al Presidente José Manuel Balmaceda, de 1949³.

\section{LA ESCENA CULTURAL}

Desde 1945 Europa asiste al retorno, a la escena cultural, de sus grandes maestros que exiliados o refugiados en provincias, reciben los reconocimientos y homenajes debidos, sus trabajos son difundidos en libros y muestras itinerantes, consolidando definitivamente el arte moderno. A su vez, los museos se reconstruyen, exhiben sus obras preciadas y comienzan una sistemática labor de extensión y educación, más cercana al público y estudiosos. Algunos ejemplos son notables. En 1946 Henri Matisse (1869-1954) reanuda su actividad en litografía ilustrando "Cartas portuguesas" de María Alcoferado y "Visages" de Pierre Reverdy; Pablo Picasso reside en el Museo de Antibes, antiguo Palacio Grimaldi, pintado cuadros que luego dona, entre ellos "La alegría de vivir", el más elocuente de su estilo nuevo e irrefutable imagen de los momentos de tranquilidad y libertad alcanzadas. Como siempre, es él quién mejor espejea los ánimos y sensibilidades de la época ${ }^{4}$.

Dichas experiencias visuales portadoras de orientaciones estéticas y estilísticas remozadas, unidas a las apropiaciones de materiales y procesos que la tecnología del momento suministra, desencadenan acciones similares en los artistas locales, basamento que ayuda comprender el desarrollo y expansión de las modernidades visuales incubadas en el decenio del cuarenta en Chile.

\footnotetext{
${ }^{2}$ Panorama cultural de la década del cuarenta se halla en Godoy Urzúa, Hernán: La cultura chilena. Santiago: Editorial Andrés Bello, 1982.

${ }^{3}$ Secuencia cronológica de instalación de escultura urbanas se enumeran en Solanich Sotomayor, Enrique: Escultura chilena: otra mirada para su estudio. Santiago: Ediciones Amigos del Arte, 2000.

${ }^{4}$ Véase de Jaffe, Hans: El arte del siglo XX. EDAF, Ediciones y Distribuciones S.A.,
}

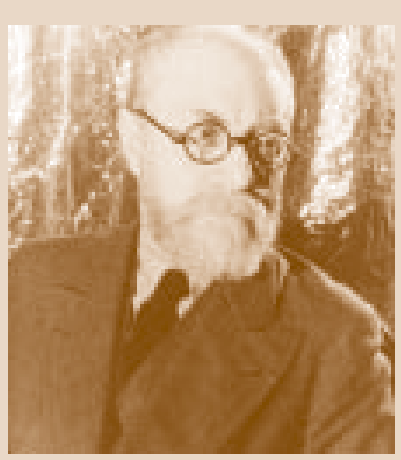

H. Matisse

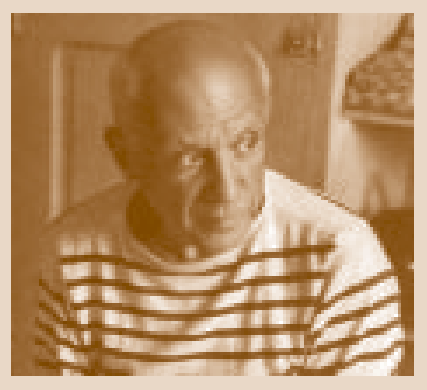

P. Picasso 
Varios factores políticos y sociales convergen. Catorce años de gobiernos radicales, entre 1938 y 1952, singularizan un período de tolerancia y estabilidad política basados en distintas alianzas de gobierno que permiten la integración participativa de amplios sectores e ideologías de la sociedad chilena. Un afán de progreso y crecimiento marca a todo el país. La creación de la Corporación de Fomento de 1939 incentiva el desarrollo económico e industrial con un plan ambicioso de electrificación y habilitación de centrales. Ello, a pareja de la apertura de escuelas industriales, técnicas y mineras.

\section{LA CUPULA DE LA BASILICA DE LOURDES}

Antaño, en la Roma Imperial, basílica es el espacio civil que funciona como tribunal de justicia, derivando su nombre de basilieos, rey en griego. Se usaba como recinto de reuniones o asambleas varias o lonja de contrataciones y comercio. De estructura rectangular más una exedra semicircular en el testero, es adaptada por los cristianos para sus primeros templos desde el siglo IV. Generalmente de tres naves, separadas entre sí por hileras de columnas son cubiertas con techumbres de madera a dos vertientes. La altura mayor de la nave central posibilita la apertura de ventanas en sus muros que iluminan el interior y en la cabecera el ábside acoge el presbiterio o lugar donde se halla en altar mayor, en sobre nivel de la planta y separada de la nave por una cancela o balaustrada. Algunas, ostentan en su entrada un atrio, por cierto descubierto.

Vale tener presente que hoy basílica es el nombre que concede la Iglesia a templos singulares y de gravitación, sea por su tamaño, calidad material de la fábrica o por significación de a quién o quiénes estén destinado.

Por otro lado, la cúpula en la arquitectura es la bóveda semiesférica a la que también se la llama, por su forma, media naranja, pero las hay también de planta elíptica y poligonal regular. Domo o duomo son sinónimos en el léxico de la arquitectura y procedimientos constructivos, impuestos para la historia del arte por el idioma italiano, denotando el segundo vocablo por extensión, catedral.

La Congregación de los Religiosos Agustinos de la Asunción, encargados de las peregrinaciones en Francia, pasan a Chile en 1890 para divulgar y administrar la parroquia de Yungay, llamada Nuestra Señora de Lourdes, en plena Quinta Normal. En los años treinta del siglo pasado se decide la erección de un segundo templo, de mayor envergadura y capacidad para atender a los feligreses. El proyecto lo asumen los arquitectos Eduardo Costabal y Andrés Garafulic, convirtiéndose en la tentativa arquitectónica sacra más contundente y sólida del período. De estilo bizantino, con planta cruciforme, de amplia nave central y dos laterales, es construida en albañi- 
lería de ladrillo y hormigón. Ostenta en sus vanos vitrales encargados a Francia, al taller de Gabriel Loire en Chartres, desplegados en 650 metros cuadrados que le imprimen al interior una atmósfera policroma y evanescente ${ }^{5}$.

Las figuras de los dieciséis profetas que circundan la cúpula de la Basílica de Lourdes, es encargada a Lily Garafulic Yankovic. Rostros de artistas, intelectuales o políticos que estima o conoce, sirven de bocetos para delinear las fisonomías definitivas de los personajes bíblicos. Así, lo llamados mayores, Isaías, Jeremías, Ezequiel y Daniel y los menores Oseas, Joel, Amós, Abdías, Miqueas, Jonás, Nahum. Habacuc, Sofonías, Ageo, Zacarías y Malaquías podrían ser reconocidos por su semejanza con los que delinea al asumir el proyecto $^{6}$.

En la iconografía sacra los profetas del Antiguo Testamento se los representa en figuras masculinas convencionales. Durante la época medieval se colocan en sus manos unas filacterias o cintas con los nombres y aureolas poligonales en sus cabezas. Pero, como fuese en el pasado, no se olvide que la exhibición de sus cuerpos importa metáforas llenas de significados y necesarias de descifrar para su correcta apreciación.

La titánica faena es emprendida en 1946 y dura parte de 1947, cerrando -según propias confesiones de la escultora-, un ciclo inicial de su promisoria labor como escultora. A la vez, no existe obra alguna en la historia de la escultura local que conceda de inmediato tanto reconocimiento y aprecio a su autor.

Su formación, conseguida en la Escuela de Bellas Artes de la Universidad de Chile, en la década del treinta, se moldea en una didáctica artística remozada, que asume las orientaciones plásticas provenientes de los círculos de avanzada de Europa y que en Chile pregonan, entre otros, Tótila Albert y Lorenzo Domínguez los más incisivos por asentar una parte de la modernidad artística y cuyos influjos de purismos morfológicos clarifican los idearios de la moza escultora.

Su trabajo anterior, comenzado con retratos y estudios de figuras, lo realiza en metales y piedras. Temprano queda marcado por afanes de depuración formal y concisión material, correspondiendo al consular proceso de aprendizaje y apropiación juveniles de procedimientos y métodos de hacer, escatimando las afinidades visuales derivadas de la inmersión en maestros y escuelas en boga.

El conjunto que se refiere son efigies de anatomías completas y ascético realismo. Frontales y cercanas a los tres metros y medio de altura cada una de ellas, adosadas a los muros curvados externos y elevadas a más de cin-

\footnotetext{
${ }^{5}$ Véase Laborde, Miguel: Templos históricos de Santiago, Santiago, El Mercurio S.A.P., 1987.

${ }^{6}$ Se cita un manuscrito del diario de viaje de la artista que anota catorce rostros, precedidos del título Apóstoles, en Cruz de Aménabar, Isabel: Lily Garafulic. Forma y signo en la escultura chilena contemporánea. Santiago: Ediciones de la Universidad Católica de Chile, 2003, p. 245.
} 
cuenta metros del suelo, cumplen solo con los ornamentos debidos en una descomunal construcción y, si se trata de buscar afinidades de estilo, habrá que mirar al románico renovado. A la vista de los espectadores asoman como altorrelieves, tan hieráticos y adustos que desafían el paso del tiempo, perpetuados en su inconmovible solemnidad, majestuoso porte y rango estético sin par al momento de ser ejecutadas.

La utilización del hormigón armado -mezcla de cemento, arena y grava-, que por medio de encofrados y armazones de hierro permiten la forma deseada- y la voluntad tenaz de situar la escultura en la mirada pública, son hitos que cambian el curso de las artes plásticas locales. Se conjugan técnicas constructivas incipientes con audacias formales, paso seguro que afianza la escultura moderna y, por obvia consecuencia, el momento preciso en que comienza un inédito arte público urbano. $\mathrm{O}$, lo que es afirmar, la consolidación de la modernidad visual.

Yendo más allá, Lily Garafulic propicia, sin sospecharlo, una fresca poética del espacio urbano y colectivo como soporte de arte, retomada luego por algunos continuadores al comprobar que la homogeneidad y fácil manejo, convierten al hormigón armado en una material adecuado a las necesidades plásticas circunstanciales, pues se amolda a la arquitectura, adecua a proyectos plásticos de morfologías y diseños complejos, resiste tensiones y vence la fuerza de la gravedad. En breve, ella y esa realización de casi sesenta años atrás, vaticinan la renovación en lo atinente de la escultura de gran formato en la ciudad, al inaugurar una alternativa citadina de imaginarios encantados, místicos y religiosos que concurren a la educación estética de la urbe. Mérito más que superior e inigualado. 


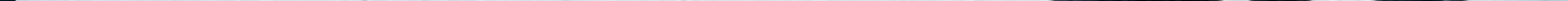




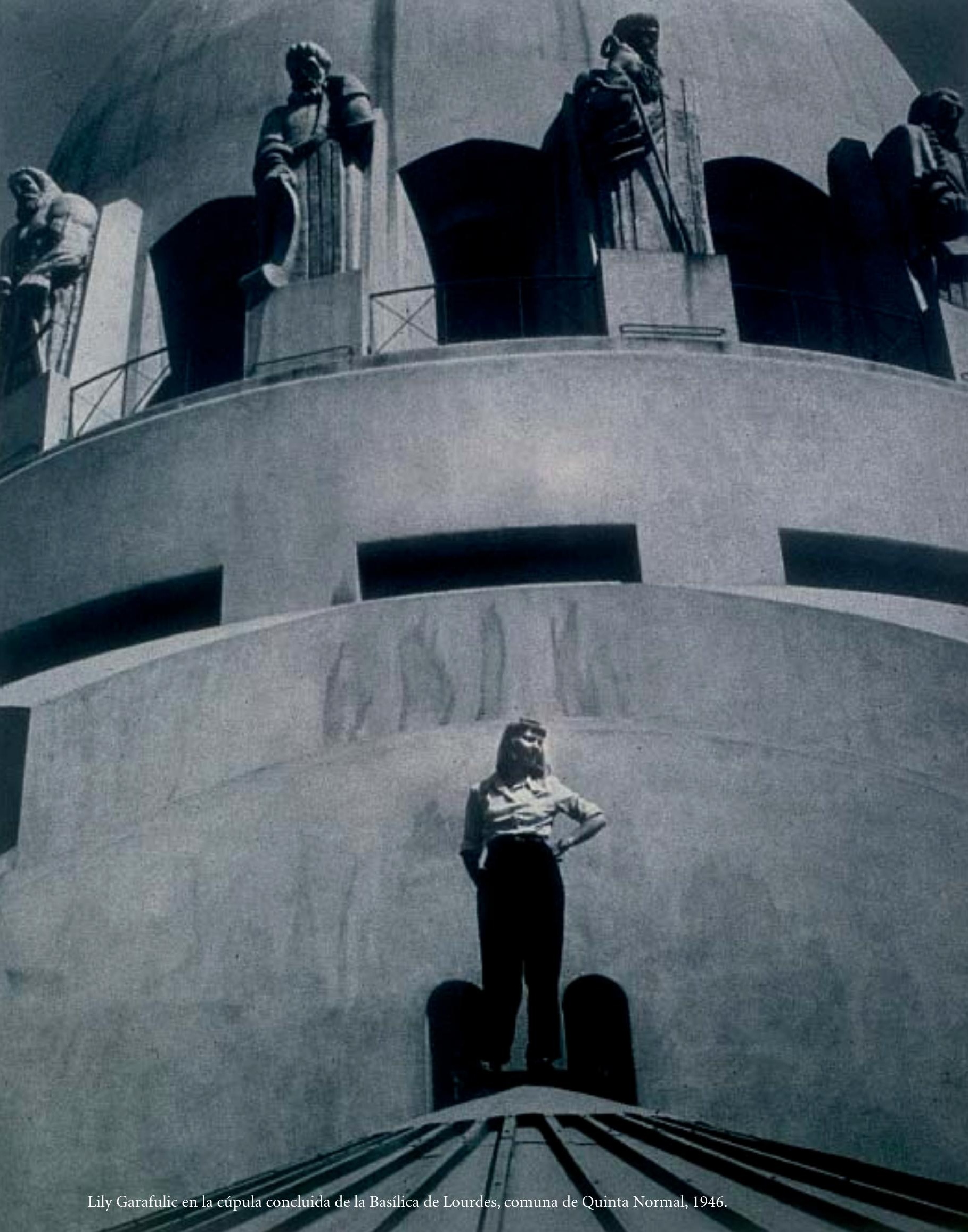




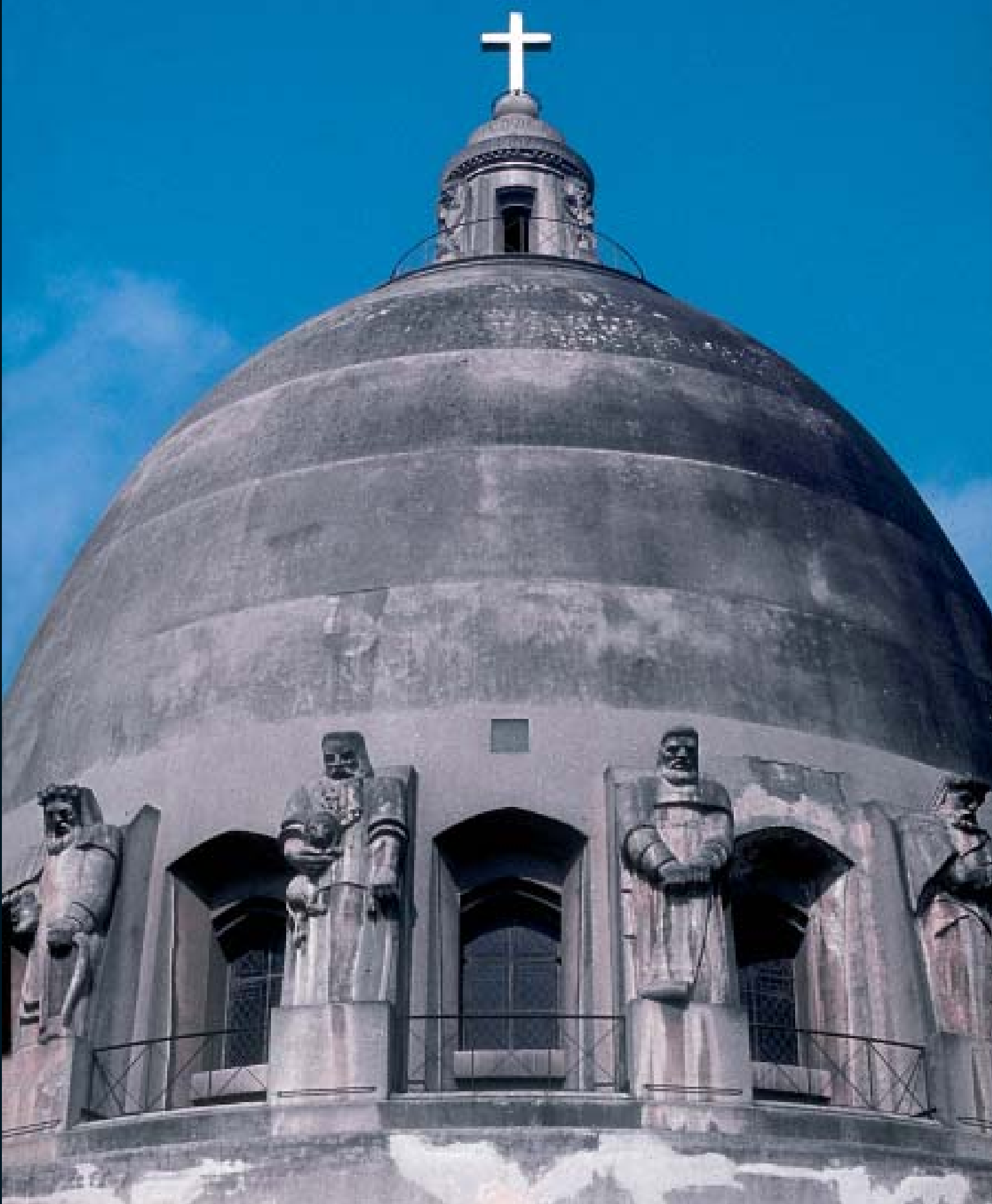

Vista de los profetas en la Cúpula de la Basílica de Lourdes, hormigón armado, comuna de Quinta Normal, 1946. Proyecto arquitectónico de Andrés Garafulic y Eduardo Costabal. 

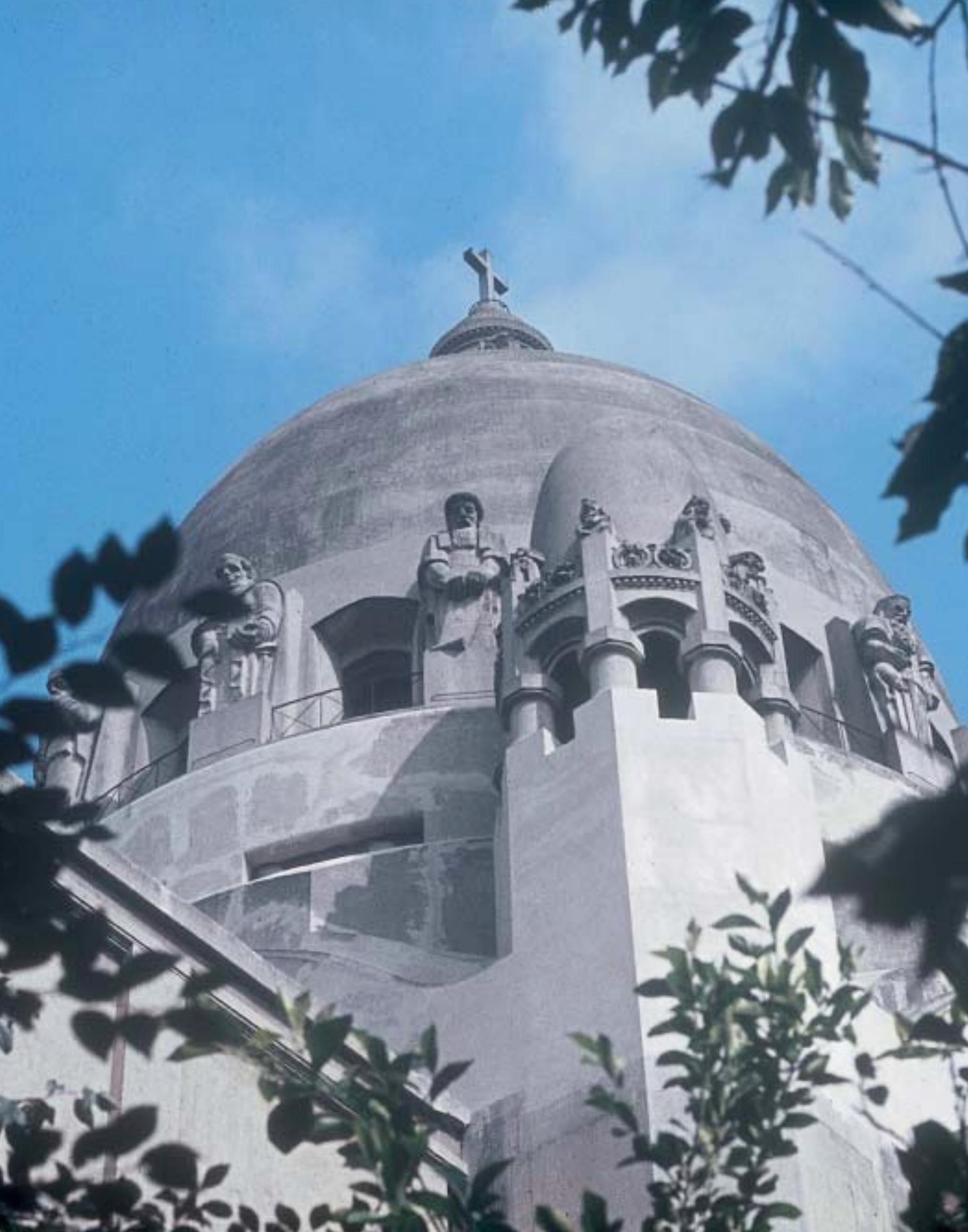